Proc. Indian Acad. Sci. (Chem. Sci.), Vol. 96, No. 6, April 1986, pp. 449-458,

(C) Printed in India.

\title{
Synthesis and structure of some interesting oxides of bismuth $\dagger$
}

\author{
J GOPALAKRISHNAN \\ Solid State and Structural Chemistry Unit, Indian Institute of Science, Bangalore 560012, \\ India
}

\begin{abstract}
Synthesis and structures of several new oxides containing bismuth are described. Three types of structures are common among the multinary oxides containing trivalent bismuth. They are the sillenite structure of $\gamma-\mathrm{Bi}_{2} \mathrm{O}_{3}$, the layered peroyskite structure of Aurivillius phases and the pyrochlore structure. The influence of $\mathrm{Bi}^{3+}: 6 s^{2}$ lone pair electrons is seen in all the three structures. In transition metal oxides containing trivalent bismuth, $d^{\circ}$ cations $\left(\mathrm{Ti}^{4+}, \mathrm{Nb}^{\mathrm{s+}}, \mathrm{W}^{6+}\right)$ stabilize the layered perovskite structure, while cations containing partially-filled $d$ orbitals $\left(\mathrm{V}^{4+}, \mathrm{Cr}^{3+}, \mathrm{Fe}^{3+}\right)$ favour pyrochlore-related structures. Ferroelectric distortion of $M \mathrm{O}_{6}$ octahedra of the $d^{\circ}$ cations seems to play an important role in stabilizing layered perovskite structures.
\end{abstract}

Keywords. Bismuth oxides; synthesis; structures; sillenites; Aurivillius (layered peroyskite) phases; pyrochlores,

\section{Introduction}

Solid compounds containing bismuth, particularly the oxides, exhibit a rich structural chemistry. Besides the binary oxide, $\mathrm{Bi}_{2} \mathrm{O}_{3}$, bismuth forms a large number of multinary oxides where the formal oxidation state of the element is either $3+$ or $5+$. Although the radius of $\mathrm{Bi}^{3+}\left(1.16 \mathrm{~A}\right.$ in VIII coordination) is comparable to that of $\mathrm{La}^{3+}(1.17 \mathrm{~A}$ in VIII coordination), there is little structural similarity between the solid compounds of $\mathrm{Bi}^{3+}$ and $\mathrm{La}^{3+}$ (Wells 1974). In many of the bismuth compounds, the coordination around the metal is unsymmetrical, all the anions being bonded to one side of the cation. Typical examples of unsymmetrical coordination around $\mathrm{Bi}^{3+}$ in some of its oxides are shown in figure 1 . The unique structural chemistry of $\mathrm{Bi}^{3+}$ oxides can be traced to the presence of stereoactive $6 s^{2}$ lone pair electrons on the cation.

The influence of $s^{2}$ lone pair electrons on the structural chemistry of lone pair cations such as $\mathrm{Bi}^{3+}, \mathrm{Sb}^{3+}, \mathrm{Pb}^{2+}$ and $\mathrm{Tl}^{+}$has been discussed in the literature. Following the early attempts of Sidgwick and Powell (1940) and Gillespie and Nyholm (1957), who introduced the valence shell electron pair repulsion theory to rationalize the geometries of molecules containing lone pair atoms, Orgel (1959) invoked hybridization of the outer $6 s$ and $6 p$ orbitals to explain the observed stereochemistries of lone pair cations. Typically, in compounds of $\mathrm{TI}^{+}, \mathrm{Pb}^{2+}$ and $\mathrm{Bi}^{3+}$, the $6 s$ orbital mixes with the empty $6 \mathrm{p}$ orbitals which are separated by $\sim 6 \mathrm{eV}$, the lone pair taking up one of the hybridized $6 \mathrm{~s}$ $6 p$ orbitals and the anions being bonded to the remaining orbitals. Together with the lone pair orbital, the anions complete a distorted polyhedron around the cation. Orgel (1959) has shown that the unsymmetrical coordination polyhedra of the lone pair cations can be derived by a distortion of regular octahedron, cube or square-antiprism.

† Contribution No. 345 from the Solid State and Structural Chemistry Unit. 


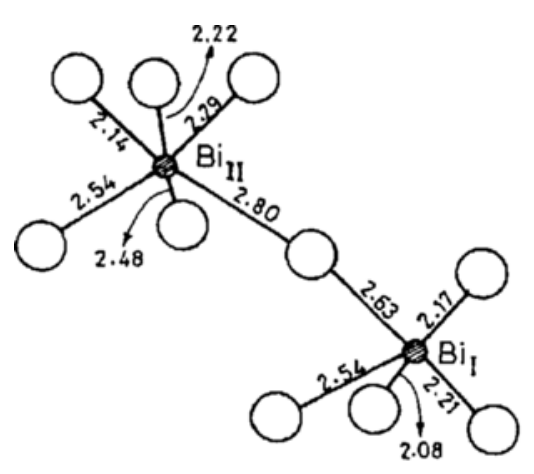

(a)

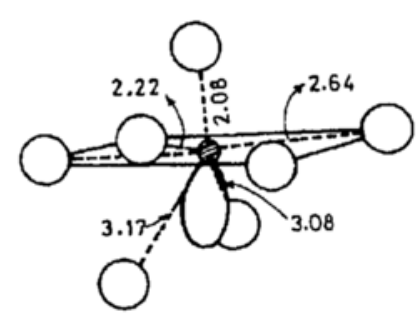

(c)

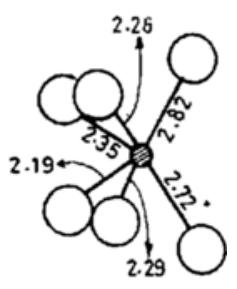

(b)

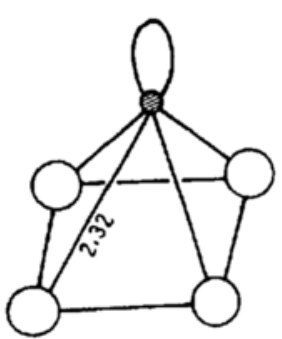

(d)

Q Bismuth $\bigcirc$ oxygen

Figure 1. Coordination polyhedra around $\mathrm{Bi}^{3+}$ in some bismuth oxides showing the influence of the $6 s^{2}$ lone pair. (a) $\alpha-\mathrm{Bi}_{2} \mathrm{O}_{3}$, (b) $\mathrm{BiRe}_{2} \mathrm{O}_{6},\left(\right.$ c) $\mathrm{Bi}_{24} \mathrm{Ge}_{2} \mathrm{O}_{40}$ and (d) layered perovskites, e.g. $\mathrm{Bi}_{4} \mathrm{Ti}_{3} \mathrm{O}_{12}$.

Andersson and Aström (1972) have pointed out that the lone pair electrons indeed take up a volume comparable to that of an anion in solids where the lone pair is stereoactive.

Unlike $\mathrm{Bi}^{3+}, \mathrm{Bi}^{3+}$ adopts symmetrical (octahedral) coordination in its solid compounds. $\mathrm{Bi}^{5+}$ however is an unstable oxidation state being stabilized in fluorides and in some ternary oxides containing electropositive alkali or alkaline-earth metals.

There is considerable current interest in the oxides of bismuth in view of the interesting structures and properties exhibited by them (see, for example, Watanabe 1984, Tsubaki and Koto 1984). The present paper describes some of the work carried out in this laboratory on the synthesis and structures of novel metal oxides containing bismuth. The oxides investigated belong mainly to the sillenite family related to $\gamma$ $\mathrm{Bi}_{2} \mathrm{O}_{3}$ (Aurivillius and Sillén 1945), the Aurivillius family of layered perovskites containing $\left(\mathrm{Bi}_{2} \mathrm{O}_{2}\right)$ layers (Aurivillius 1949) and the pyrochlore family. In several of these oxides, influence of the $6 s^{2}$ lone pair on the structure is seen.

\section{Experimental}

Oxides containing bismuth and one or more of the following transition metals, Ti, $\mathrm{V}$, $\mathrm{Nb}, \mathrm{W}, \mathrm{Cr}, \mathrm{Fe}$ or lanthanide, were prepared. Preparations were carried out by the 
conventional ceramic method as well as by low-temperature methods. A lowtemperature 'wet' method involving reaction in a high alkaline medium was employed for the preparation of sillenite phases in the $\mathrm{Bi}-M-\mathrm{O}(M=\mathrm{Mn}, \mathrm{Fe}, \mathrm{Co})$ systems (Ramanan and Gopalakrishnan 1985). Oxides of the general formula, $\mathrm{Bi}_{2-x} M_{x} \mathrm{WO}_{6}(M=\mathrm{Cr}, \mathrm{Fe})$ were prepared from aqueous solutions of the component metal nitrates and ammonium tungstate (Ramanan et al 1983). Structural characterization of the oxides prepared were made by powder x-ray diffraction, electron diffraction, IR absorption spectroscopy and magnetic susceptibility measurements. The details are given elsewhere (Ramanan 1984).

\section{Results and discussion}

\subsection{Sillenite phases}

Ternary bismuth oxides related to $\gamma-\mathrm{Bi}_{2} \mathrm{O}_{3}$ possessing the general formula, $\mathrm{Bi}_{26-x} M_{x} \mathrm{O}_{40-y}$, where $M=\mathrm{Si}, \mathrm{Ge}, \mathrm{Sn}, \mathrm{Ti}$ and $x=2$ or $M=\mathrm{Fe}, \mathrm{Zn}$ etc., and $x<2$ are known as sillenite phases (Aurivillius and Sillen 1945; Levin and Roth 1964). They adopt a $B C C$ structure (space group $I 23$ ) with $a \simeq 10-20 \mathrm{~A}$. In this structure, $\mathrm{Bi}^{3+}$ has an unusual $(5+2)$ oxygen coordination (figure 1) clearly revealing the influence of the $\mathrm{Bi}^{3+}: 6 \mathrm{~s}^{2}$ lone pair on the structure (Abrahams et al 1967). The bismuth-oxygen polyhedra share corners and edges to form a $\mathrm{Bi}_{24} \mathrm{O}_{40}$ cluster. Although it is generally believed that the ternary $M$ atoms in this structure occupy the tetrahedral 2(a) sites, as for example in the ideal cases of $\mathrm{Bi}_{24} \mathrm{Si}_{2} \mathrm{O}_{40}$ and $\mathrm{Bi}_{24} \mathrm{Ge}_{2} \mathrm{O}_{40}$, the concentration of $M$ atoms in a number of sillenite phases is far in excess of the ideal composition. For instance, cubic phases of approximate composition $\mathrm{BiMO}_{3}(M=\mathrm{Al}, \mathrm{Co}, \mathrm{Ni})$ have been reported in the literature (Tomashpolskii et al 1969; Bucci 1971), but the details of their structures are not known. It is possible that such systems adopt sillenite structure where part of bismuth in the $\mathrm{Bi}_{24} \mathrm{O}_{40}$ cluster is substituted by $M$ atoms.

Our investigations of sillenite phases in the $\mathrm{Bi}_{2} \mathrm{O}_{3}-M \mathrm{O}_{x}(M=\mathrm{Mg}, \mathrm{Al}, \mathrm{Mn}, \mathrm{Fe}$, Co and Ni) systems (Ramanan et al 1981; Ramanan and Gopalakrishnan 1985) have revealed that two kinds of sillenite phases are formed in many of these systems. One is the bismuth-rich phase which corresponds to the normal sillenite structure and the other is an $M$-rich phase which is formed especially when the preparation is carried out by a low-temperature method. As a typical case, in the Bi-Co-O system, we prepared two sillenite phases, $\mathrm{Bi}_{45} \mathrm{CoO}_{40}$ and $\mathrm{Bi}_{10} \mathrm{Co}_{16} \mathrm{O}_{38}$. The former corresponds to the normal sillenite phase and its structure ( $B C C, a=10.11 \mathrm{~A})$ and magnetic susceptibility $\left(\mu_{\text {eff }}=5.00 \mathrm{BM}, \mathrm{Co}^{3+}(\mathrm{S}=2)\right.$ at the tetrahedral site) are similar to those of $\mathrm{Bi}_{25} \mathrm{CoO}_{40}$ prepared by the high temperature method (Devalette et al 1982). The cobalt-rich phase, $\mathrm{Bi}_{10} \mathrm{Co}_{16} \mathrm{O}_{38}$, also possesses the sillenite structure with nearly identical lattice parameter. The phase is formulated as $\left(\mathrm{Co}^{2+}\right)_{2}\left[\mathrm{Bi}_{10}^{3+} \mathrm{Co}_{14}^{3+}\right] \mathrm{O}_{38}$ indicating that a substantial portion of bismuth in the $\mathrm{Bi}_{24} \mathrm{O}_{40}$ cluster of the sillenite structure is replaced by trivalent cobalt. Structural evidence that this formulation is most likely to be correct is provided by a refinement of $\mathrm{x}$-ray powder diffraction intensities (table 1) on the basis of this model. The IR absorption spectrum of the cobalt-rich phase (figure 2) is different from the spectra of normal sillenites. A band around $820 \mathrm{~cm}^{-1}\left(v_{3}\right.$ of $\mathrm{MO}_{4}$ tetrahedron) and a group of sharp bands in the region $400-600 \mathrm{~cm}^{-1}$ which are characteristic of the $\mathrm{Bi}_{24} \mathrm{O}_{40}$ cluster (Betsch and White 1978; Devalette et al 1982) are 
Table 1. Refinement of $x$-ray powder diffraction intensities of $\left(\mathrm{Co}^{2+}\right)_{2}\left[\mathrm{Bi}_{10}^{3+} \mathrm{Co}_{14}^{3+}\right] \mathrm{O}_{3 \mathrm{a}}$ in the sillenite structure.

\begin{tabular}{|c|c|c|c|c|c|}
\hline$h k l$ & $I(\mathrm{obs})$ & $I(\text { calc })^{(\theta)}$ & $h k !$ & $I$ (obs) & $I(\mathrm{calc})^{(\omega)}$ \\
\hline 220 & 2 & 6 & $611\}$ & 30 & 34 \\
\hline 310 & 100 & 92 & $532\}$ & & \\
\hline 222 & 30 & 32 & 631 & 12 & 19 \\
\hline 321 & 90 & 96 & 710 & & \\
\hline 400 & 11 & 12 & 550 & 14 & 20 \\
\hline 411$\}$ & 12 & 15 & 543 & & \\
\hline 330 & 12 & 13 & 721 & & \\
\hline 420 & 8 & 6 & 552 & 6 & 7 \\
\hline 332 & 5 & 2 & 633 & & \\
\hline 422 & 25 & 27 & $651\}$ & 4 & 8 \\
\hline 431$\}$ & 35 & 44 & 7325 & 4 & \\
\hline 510$\}$ & נJ & 4 & 7417 & & \\
\hline 521 & 6 & 10 & 811 & 0 & 5 \\
\hline 530$\}$ & 21 & 24 & 554 & & \\
\hline 433 & & & 653 & 12 & 12 \\
\hline $\left.\begin{array}{l}600 \\
442\end{array}\right\}$ & 15 & 20 & $\left.\begin{array}{l}660 \\
822\end{array}\right\}$ & 10 & 11 \\
\hline
\end{tabular}

(a) Intensities were calculated assuming that the structure is similar to $\mathrm{Bi}_{24} \mathrm{Ge}_{2} \mathrm{O}_{40}$. The refined positional parameters are $(2 \mathrm{Co})(2 a), 0,0,0,(10 \mathrm{Bi}+14 \mathrm{Co})(24 f), 0.826(4)$, 0.684 (1), 0.991 (2), O (1) (24 f), 0.856 (21), 0.761 (16), 0.519 (15), O (2) (8c), 0.811 (15), $0.811(15), 0.811(15) ; 0(3)(8 c), 0.093(8), 0.093(8), 0.093(8)$. The occupancy factor for oxygen is $(38 / 40) . R_{w}=15 \%$.

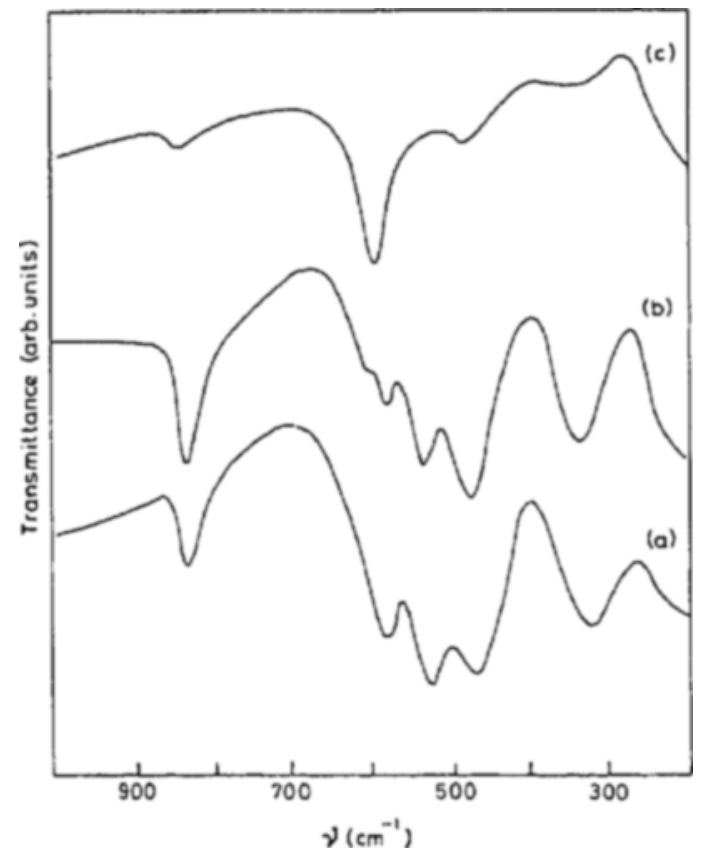

Figure 2. Infrared absorption spectra of sillenite phases. (a) $\mathrm{Bi}_{25} \mathrm{FeO}_{40}$, (b) $\mathrm{Bi}_{25} \mathrm{CoO}_{40}$ and (c) $\mathrm{Bi}_{10} \mathrm{Co}_{16} \mathrm{O}_{38}$. 
seen in $\mathrm{Bi}_{25} \mathrm{CoO}_{40}$ and $\mathrm{Bi}_{25} \mathrm{FeO}_{40}$. In the cobalt-rich phase, a new band at $575 \mathrm{~cm}^{-1}$, which may be due to $\left(\mathrm{Co}^{2+} \mathrm{O}_{4}\right)$ tetrahedra, appears while the strong band at $820 \mathrm{~cm}^{-1}$ disappears. Other changes in the spectrum are consistent with the substitution of part of the bismuth in the $\mathrm{Bi}_{24} \mathrm{O}_{40}$ cluster by $\mathrm{Co}^{3+}$ ions. The present investigation thus reveals the existence of a new type of sillenite phase wherein part of the bismuth at the $(24 f)$ sites of the sillenite structure are substituted by transition metal ions such as $\mathrm{Co}^{3+}$ and $\mathrm{Fe}^{3+}$.

\subsection{Aurivillius phases}

Layered perovskite oxides of bismuth of the general formula, $\left(\mathrm{Bi}_{2} \mathrm{O}_{2}\right)^{2+}\left[A_{n-1} B_{n} \mathrm{O}_{3 n+1}\right]^{2-}$, where $A$ is a large cation like $\mathrm{Ba}, \mathrm{Pb}, \mathrm{Sr}, \mathrm{Ca}, \mathrm{Bi}, \mathrm{K}$ and $\mathrm{Na}$ and $B$ is a smaller cation such as $\mathrm{Ti}, \mathrm{Nb}, \mathrm{W}, \mathrm{Fe}$ etc., stable in octahedral coordination, are known as Aurivillius phases (Aurivillius 1949). These solids adopt a layered structure consisting of alternating $\mathrm{PbO}$-like $\left(\mathrm{Bi}_{2} \mathrm{O}_{2}\right)$ layers and $\left[A_{n-1} B_{n} \mathrm{O}_{3 n+1}\right]$ perovskite slabs (figure 3). They crystallize in orthorhombic (pseudotetragonal) structures with $a \simeq b \simeq 5.4 \mathrm{~A}$; the length of the $c$-axis varies with the thickness of the perovskite slab (n-value) (Newnham et al 1971; Hutchison et al 1977). We have prepared a number of new Aurivillius phases and examined their structures using $x$-ray and electron diffraction as well as electron microscopy (Gopalakrishnan et al 1984). The investigations have revealed a number of interesting features which are briefly presented here.

In the $\mathrm{Bi}_{2} \mathrm{O}_{3}-\mathrm{WO}_{3}$ system, we visualized the existence of a new homologous series, $\mathrm{Bi}_{2} \mathrm{~W}_{n} \mathrm{O}_{3 n+3}$, as a special case of the more general Aurivillius family, where the perovskite component of the latter is replaced by $\mathrm{WWO}_{3}$ component of corner-sharing $\mathrm{WO}_{6}$ octahedra (figure 4). The two known phases in the system, $\mathrm{Bi}_{2} \mathrm{WO}_{6}$ and $\mathrm{Bi}_{2} \mathrm{~W}_{2} \mathrm{O}_{9}$ (Watanabe and Goto 1978), may be regarded as $n=1$ and $n=2$ members of this family. We have obtained evidence for the existence of the $n=3$ member of this family by high resolution electron microscopic investigations of nominal $n=3$ compositions (Jefferson et al 1982). The $n=3$ member exists as a disordered intergrowth together with the more stable $n=1$ and $n=2$ members of this family. More importantly, we have synthesized a new family of ordered (recurrent) intergrowth phases of the general formula, $\mathrm{Bi}_{4} A_{m+n-2} B_{m+n} \mathrm{O}_{3(m+n)+6}$, which are formed between $n$ and $n+1 \quad(=m)$ members of the Aurivillius family (figure 5) (Gopalakrishnan et al 1984). The unit cell parameters of the new members of this series as derived from the $\mathrm{x}$-ray and electron diffraction data are given in table 2 . Lattice image of a typical member of this series is shown in figure 6 . Although some members of this family were reported as isolated instances (Horiuchi et al 1977), our investigations have revealed the existence of a new homologous series of oxides based on ordered intergrowth of members of the Aurivillius family of oxides. A particularly interesting member of this homologous series is $\mathrm{Bi}_{5} \mathrm{Nb}_{3} \mathrm{O}_{15}$ which is formed by intergrowth of $n=1$ and $n=2$-like units of the Aurivillius family. It is to be noted that the individual $n=1$ and $n=2$ members do not exist in this system. Formation of intergrowth phases in this family seems to have its origin in the minimization of elastic strain energy when the intergrowth occurs between the constituent units (Kikuchi 1979; Gopalakrishnan et al 1984; Jefferson et al 1984).

Structural data reveal that $\mathrm{Bi}^{3+}: 6 s^{2}$ lone pair plays a significant role in stabilizing the Aurivillius phases (Newnham et al 1971; Watanabe 1984). Although $\mathrm{Bi}^{3+}$ has a pyramidal coordination with four oxygen in the $\left(\mathrm{Bi}_{2} \mathrm{O}_{2}\right)$ layer $(\mathrm{Bi}-\mathrm{O} \sim 2 \cdot 2-2 \cdot 4 \mathrm{~A})$, it 


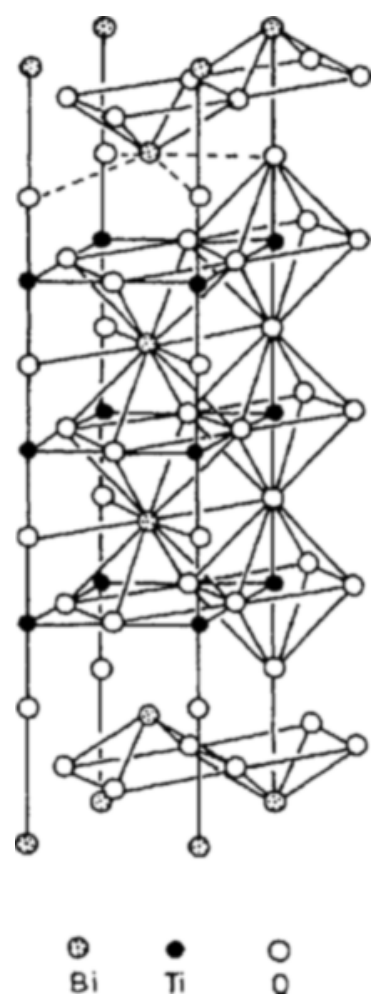

Figure 3. Idealised structure of an Aurivillius phase, $\mathrm{Bi}_{4} \mathrm{Ti}_{3} \mathrm{O}_{12}$. The distorted square antiprismatic coordination around $\mathrm{Bi}^{3+}$ in $\left(\mathrm{Bi}_{2} \mathrm{O}_{2}\right)$ layer is indicated.

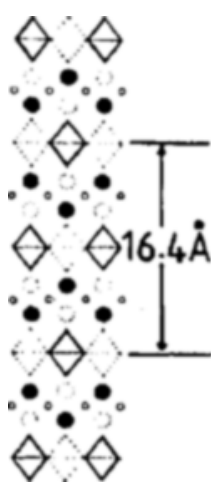

(a)

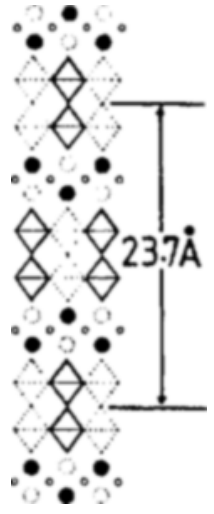

(b)

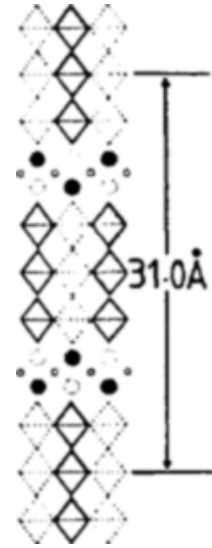

(c)
Figure 4. Idealised representations of the structures of $\mathrm{Bi}_{2} \mathrm{~W}_{n} \mathrm{O}_{3 n+3}$ members. (a) $\mathrm{Bi}_{2} \mathrm{WO}_{6}$, (b) $\mathrm{Bi}_{2} \mathrm{~W}_{2} \mathrm{O}_{9}$ and (c) $\mathrm{Bi}_{2} \mathrm{~W}_{3} \mathrm{O}_{12}$ (from Jefferson et al 1982).

forms additional weak bonds with the perovskite slabs which appear to be essential for the stability of the structure. In $\mathrm{Bi}_{2} \mathrm{WO}_{6}(n=1$ member $), \mathrm{Bi}^{3+}$ in the $\left(\mathrm{Bi}_{2} \mathrm{O}_{2}\right)$ layer is coordinated to an additional oxygen of the $\mathrm{WO}_{6}$ octahedron at a distance of $2.49 \mathrm{~A}$ in such a way as to accommodate the $6 s^{2}$ lone pair (Watanabe 1984). In the higher members of the Aurivillius family, each bismuth in the $\left(\mathrm{Bi}_{2} \mathrm{O}_{2}\right)$ layer is surrounded by eight oxygen atoms, four from the layer and four more from the perovskite slab at longer distances, the coordination polyhedron around bismuth being a distorted square-antiprism (figure 3). That the $\mathrm{Bi}^{3+}: 6 s^{2}$ lone pair plays a crucial role in the stability of Aurivillius phases is seen from the fact that the structure is destroyed by the substitution of other ions of similar size in the $\left(\mathrm{Bi}_{2} \mathrm{O}_{2}\right)$ layer (Armstrong and Newnham 1972).

\subsection{Pyrochlores}

It is known that $6 s^{2}$ lone-pair cations $\left(\mathrm{Ti}^{+}, \mathrm{Pb}^{2+}, \mathrm{Bi}^{3+}\right)$ stabilize a defect-pyrochlore structure in a number of ternary oxides (Longo et al 1969). We have prepared two new oxides containing bismuth, $\mathrm{BiCrWO}_{6}$ and $\mathrm{BiFeWO}_{6}$, that adopt a defect-pyrochlore 

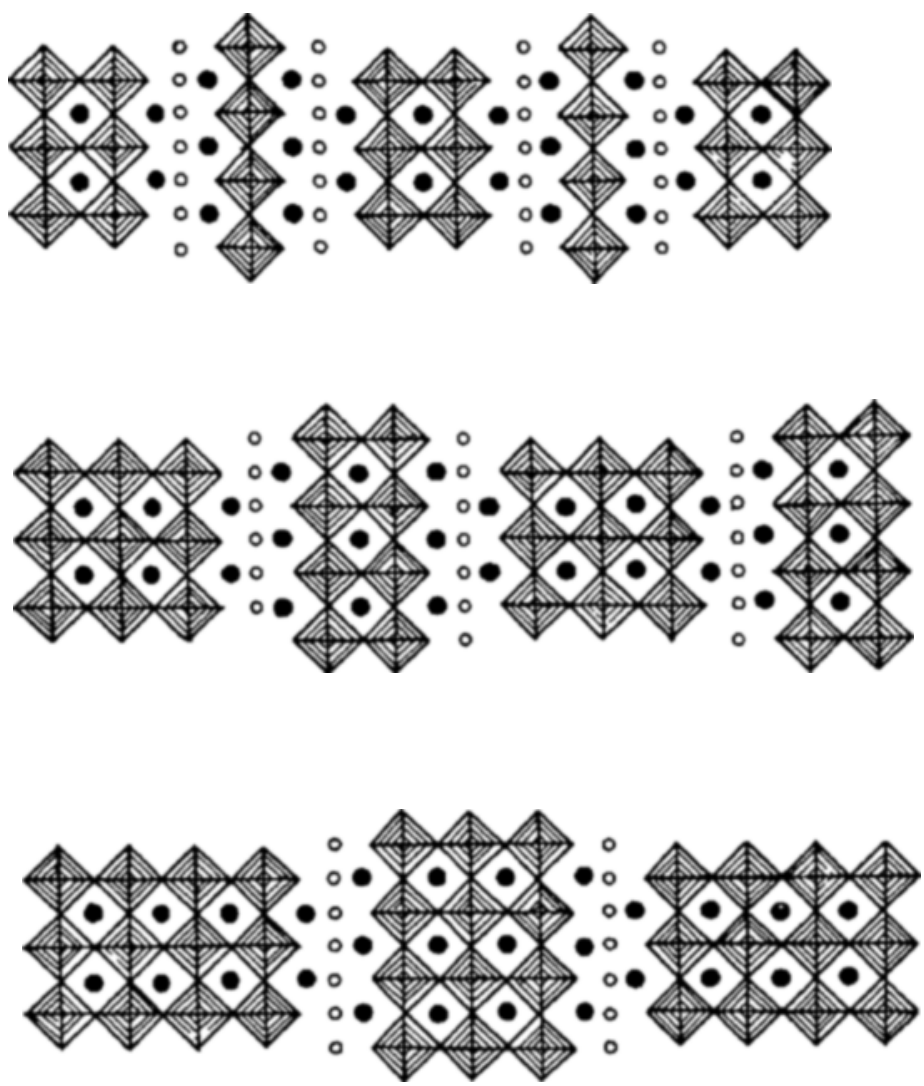

Figure 5. Idealised representations of the structures of intergrowth Aurivillius phases (from Gopalakrishnan et al 1984).

Table 2. Unit cell parameters of intergrowth Aurivillius phases

\begin{tabular}{lcccc}
\hline & \multirow{2}{*}{$\begin{array}{c}\text { Perovskite } \\
\text { layer } \\
\text { Compound }\end{array}$} & \multicolumn{3}{c}{ Lattice parameters (A) } \\
\cline { 3 - 5 } & sequence & $a$ & $b$ & $c$ \\
\hline $\mathrm{Bi}_{5} \mathrm{Nb}_{3} \mathrm{O}_{15}$ & 1,2 & 5.464 & 5.464 & 20.89 \\
$\mathrm{Bi}_{7} \mathrm{Ti}_{4.5} \mathrm{~W}_{0.5} \mathrm{O}_{21}$ & 2,3 & 5.412 & 5.396 & 29.01 \\
$\mathrm{Bi}_{9} \mathrm{Ti}_{6} \mathrm{CrO}_{27}$ & 3,4 & 5.439 & 5.438 & 36.73 \\
$\mathrm{Bi}_{9} \mathrm{Ti}_{6} \mathrm{FeO}_{27}$ & 3,4 & 5.460 & 5.440 & 37.08 \\
$\mathrm{BaBi}_{12} \mathrm{Ti}_{7} \mathrm{O}_{27}$ & 3,4 & 5.444 & 5.444 & 37.45 \\
$\mathrm{BaBi}_{12} \mathrm{Ti}_{10} \mathrm{O}_{39}$ & $3,3,4$ & 5.428 & 5.428 & 53.68 \\
\hline
\end{tabular}

structure (Ramanan et al 1983). The regular pyrochlore structure adopted by oxides of $A_{2} B_{2} \mathrm{O}_{7}$ composition is cubic (space group $F d 3 m, Z=8$ ) where the large $A$ cation occupies 8-coordinated (16d) sites and the smaller $B$ cations take up octahedral (16c) sites (McCauley 1980; Subramanian et al 1983). For $A B_{2} \mathrm{O}_{6}$ oxides crystallizing in the $F d 3 m$ space group, two different structures are possible (Babel 1972): (i) a defect pyrochlore structure in which the (16d) sites are randomly occupied by eight $A$ atoms 


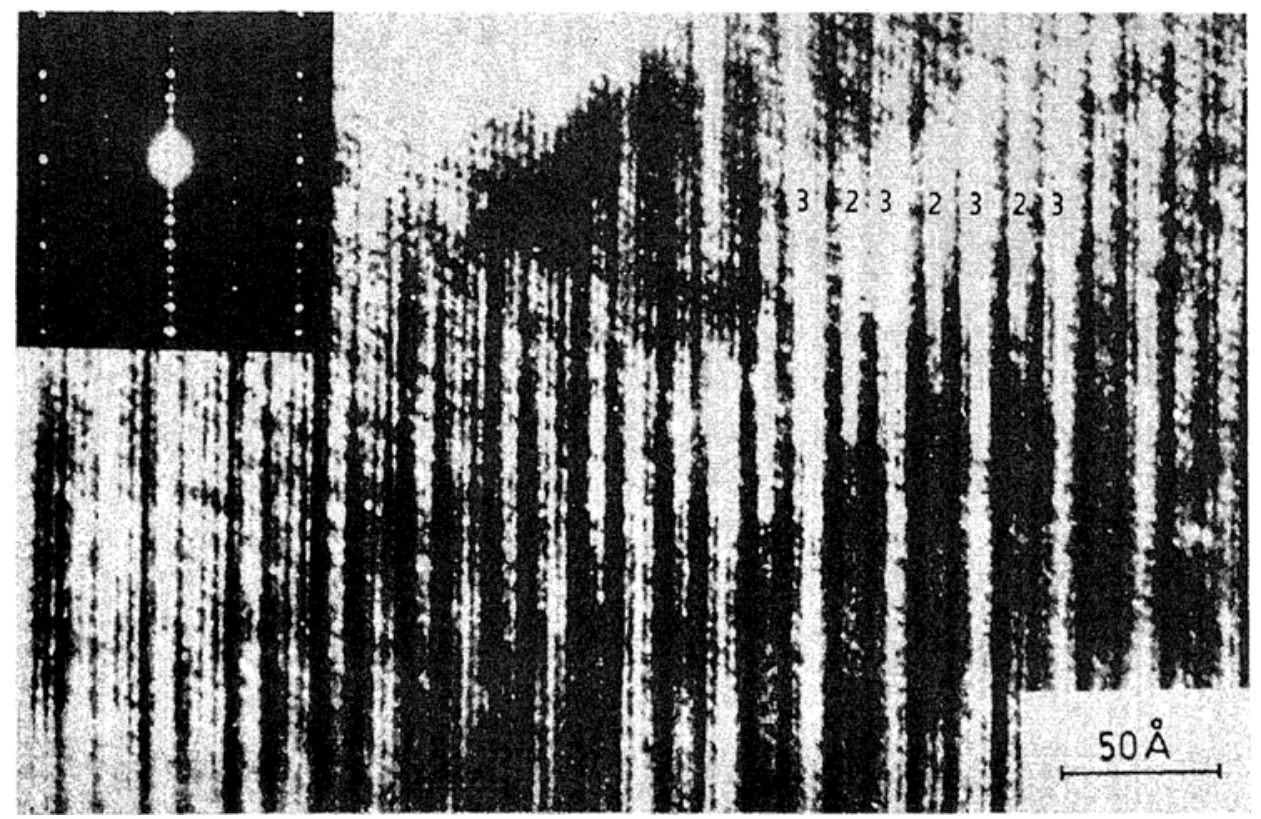

Figure 6. Lattice image of $\mathrm{Bi}_{7} \mathrm{Ti}_{4.5} \mathrm{~W}_{0.5} \mathrm{O}_{21}$ showing ordered (recurrent) intergrowth of $n=2$ and $n=3$ members of the Aurivillius family. The corresponding electron diffraction pattern is shown. The electron beam is parallel to [110].

and the $(8 b)$ anion sites are vacant and (ii) the $\mathrm{RbNiCrF}_{6}$ structure where the $\mathrm{Rb}$ atoms occupy the $(8 b)$ sites leaving the $(16 d)$ sites completely vacant. A refinement of $\mathrm{x}$-ray powder diffraction intensities reveals that both $\mathrm{BiCrWO}_{6}$ and $\mathrm{BiFeWO}_{6}$ crystallize in a defect pyrochlore structure and not in the $\mathrm{RbNiCrF}_{6}$ structure (Ramanan et al 1983). The defect pyrochlores are metastable having been formed because of the low temperature of synthesis. At high temperatures, they transform irreversibly to a tetragonal tungsten bronze structure with $a \simeq 12.40$ and $c \simeq 3.65 \mathrm{~A}$.

More interestingly, we have obtained pyrochlore phases in several systems such as $\mathrm{Bi}-\mathrm{V}-\mathrm{O}, \mathrm{Bi}-M-\mathrm{Cr}-\mathrm{O}$ and $\mathrm{Bi}-M-\mathrm{Fe}-\mathrm{O}(M=\mathrm{Nb}$ or $\mathrm{Ta})$ whenever we have attempted to prepare layered perovskite (Aurivillius) phases (Ramanan et al 1985). Thus, the vanadium analogue of the layered perovskite $\mathrm{Bi}_{4} \mathrm{Ti}_{3} \mathrm{O}_{12}$ cannot be prepared; instead attempts to prepare this phase by heating appropriate mixtures of $\mathrm{Bi}_{2} \mathrm{O}_{3}, \mathrm{~V}_{2} \mathrm{O}_{3}$ and $\mathrm{V}_{2} \mathrm{O}_{5}$ in sealed evacuated tubes resulted in the formation of a defect pyrochlore phase of composition $\mathrm{Bi}_{1.33} \mathrm{~V}_{2} \mathrm{O}_{6}$ which adopts an orthorhombic structure with $a=7.04$, $b=7.55$ and $c=10.70 \mathrm{~A}$. Similarly, attempts to prepare intergrowth Aurivillius phases (cf. \$3.2) of composition $\mathrm{Bi}_{7} \mathrm{Nb}_{3} \mathrm{Cr}_{2} \mathrm{O}_{21}$ and $\mathrm{Bi}_{7} \mathrm{Nb}_{3} \mathrm{Fe}_{2} \mathrm{O}_{21}$, which would be isostructural with $\mathrm{Bi}_{7} \mathrm{Ti}_{4.5} \mathrm{~W}_{0.5} \mathrm{O}_{21}$ (Gopalakrishnan et al 1984), have always resulted in pyrochlore phases $\mathrm{Bi}_{2} \mathrm{NbCrO}_{7}$ and $\mathrm{Bi}_{2} \mathrm{NbFeO}_{7}$. These results have led us to examine in general the relative stabilities of layered perovskite and pyrochlore structures in transition metal oxides containing bismuth (Ramanan et al 1985). It appears that $d^{\circ}$ cations stabilize the layered perovskite strucutre, while cations containing partially filled $d$ orbitals (which suppress ferroelectric distortion of $\mathrm{BO}_{6}$ octahedra) favour pyrochlore-related structures, the reason being that the formation of layered perovskite structure requires the presence of weak bonds between the $\left(\mathrm{Bi}_{2} \mathrm{O}_{2}\right)$ layers 
and the perovskite slabs, which entails considerable distortion of the $\mathrm{BO}_{6}$ octahedra. This distortion is possible only with $d^{\circ}$ cations such as $\mathrm{Ti}^{4+}, \mathrm{Nb}^{5+}$ or $\mathrm{W}^{6+}$ which are known to exhibit ferroelectric distortions of the perovskite structure (Goodenough and Longo 1970).

\subsection{Other bismuth oxides}

Metal oxides containing $\mathrm{Bi}^{5+}$ are relatively rare. Two interesting examples of $\mathrm{Bi}^{5+}$-containing oxides are $\mathrm{BaBiO}_{3}$ (Cox and Sleight 1979) and $\mathrm{Sr}_{2} \mathrm{Bi}_{2} \mathrm{O}_{7}$ (Knop et al 1980). $\mathrm{BaBiO}_{3}$ is a mixed-valence perovskite-related oxide containing both $\mathrm{Bi}^{3+}$ and $\mathrm{Bi}^{3+}$, while $\mathrm{Sr}_{2} \mathrm{Bi}_{2} \mathrm{O}_{7}$ containing exclusive $\mathrm{Bi}^{5+}$ adopts a weberite structure. We have attempted to synthesize similar oxides containing $\mathrm{Bi}^{\mathrm{S}+}$. We have been able to prepare weberite-related phases of the formula $\mathrm{NaLnBi}_{2} \mathrm{O}_{7-x}$ $(\mathrm{Ln}=\mathrm{La}, \mathrm{Nd}, \mathrm{Gd}$ or $\mathrm{Y} ; x=0.5)$ by a low temperature method involving decomposition of metal nitrates (Ramanan and Gopalakrishnan 1982). The weberite-related phases lose oxygen around $750^{\circ} \mathrm{C}$ giving $\mathrm{NaLnBi}_{2} \mathrm{O}_{6}$ which crystallize in a monoclinic (ordered perovskite) structure. In both the structures, $\mathrm{Bi}^{5+}$ adopts a regular octahedral oxygen coordination as expected.

\section{Acknowledgements}

The author wishes to express his grateful thanks to Professor C N R Rao, for valuable suggestions and advice. Thanks are also due to $\mathrm{Dr} A$ Ramanan who has worked on bismuth oxides for his $\mathrm{Ph}$.D. thesis.

\section{References}

Abrahams S C, Jamieson P B and Bernstein J L 1967 J. Chem. Phys. 474034

Andersson S and Astrom A 1972 in Solid State Chemistry, NBS Special Publication 364, U.S. Dept. of Commerce, Washington, $D$. C.

Armstrong R A and Newnham R E 1972 Mater. Res. Bull. 71025

Aurivillius B 1949 Ark. Kemi. 1 463, 499

Aurivillius B and Sillen L G 1945 Nature (London) 155305

Babel D 1972 Z. Anorg. Allg. Chem. 387161

Betsch R J and White W B 1978 Spectrochim. Acta A34 505

Bucci J D 1971 Ph.D. Thesis, University of Missouri-Rolla

Cox D E and Sleight A W 1979 Acta Crystallogr. B35 1

Devalette M, Darriet J, Couzi M, Mazeau C and Hagenmuller P 1982 J. Solid State Chem. 4345

Gillespie R J and Nyholm R S 1957 Q. Rev. Chem. Soc. 11339

Goodenough J B and Longo J M 1970 Landolt-Bornstein tabellen New serles III/4a (Berlin: Springer-Verlag) Gopalakrishnan J, Ramanan A, Rao C N R, Jefferson D A and Smith D J 1984 J. Solid State Chem. 55101 Horiuchi S, Kikuchi T and Goto M 1977 Acta Crystallogr. A33 701

Hutchison J L, Anderson J S and Rao C N R 1977 Proc. R. Soc. London A355 301

Jefferson D A, Gopalakrishnan J and Ramanan A 1982 Mater, Res, Bull 17269

Jefferson D A, Uppal M K, Smith D J and Rao C N R 1984 Mater. Res. Bull. 191403

Kikuchi T 1979 Mater. Res. Bull. 141561

Knop O, Demazeau G and Hagenmuller P 1980 Can. J. Chem. 582221

Levin E M and Roth R S 1964 J. Res. Natl. Bur. Stand. A68 197

Longo J M, Raccah P M and Goodenough J B 1969 Mater. Res. Bull. 4191

McCauley R A 1980 J. Appl. Phys. 51290 
Newnham R E, Wolfe R W and Dorrain J F 1971 Mater. Res. Bull. 61029

Orgel L E 1959 J. Chem. Sac. 3815

Ramanan A 1984 Solid state chemistry of novel bismuth oxides: $\gamma-\mathrm{Bi}_{2} \mathrm{O}_{3}$, Aurivillius phases, tungsten bronzes and related phases, $\mathrm{Ph} . \mathrm{D}$. thesis, Indian Institute of Science, Bangalore

Ramanan A and Gopalakrishnan J 1982 Rev. Chim. Miner. 19225

Ramanan A and Gopalakrishnan J 1985 Indian J. Chem. A24 594

Ramanan A, Gopalakrishnan J and Rao C N R 1981 Mater. Res. Bull. 16169

Ramanan A, Gopalakrishnan J and Rao C N R 1985 J. Solid State Chem. 60269

Ramanan A. Subbanna G N, Gopalakrishnan J and Rao C N R 1983 Rev. Chim. Miner. 20576

Sidgwick N V and Powell H M 1940 Proc. R. Soc. London A176 153

Subramanian M A, Aravamudan G and Subba Rao G V 1983 Prog. Solid State Chem. 1555

Tomashpolskii Yu Ya, Zubova E V, Burdina K P and Venevtsev Yu N 1969 Sov. Phys. Crystallogr. (Engl. Transi.) 13859

Tsubaki M and Koto K 1984 Mater. Res. Bull. 191613

Watanabe A 1984 Mater. Res. Bull. 19877

Watanabe A and Goto M 1978 J. Less-Common Met. 61265

Wells A F 1974 Structural inorganic chemistry 4th edn. (Oxford: University Press) 